\title{
Lesão Central de Células Gigantes - Relato de Caso
}

\author{
Central Giant Cell Lesion - Case Report \\ Lesión Central de Celdas Gigantes - Relato de Caso
}

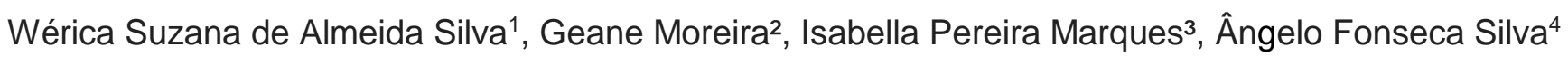

\section{RESUMO}

Objetivo: Relatar um caso clínico de uma lesão central de Células gigantes em um paciente do gênero feminino, 10 anos de idade, leucoderma, método diagnóstico e tratamento de escolha. Relato de Caso: Paciente do gênero feminino, leucoderma, 10anos de idade apresentou-se em nossos serviços clínicos com aumento de volume unilateral com expansação sintomática durante 7 meses, ao exame radiográfico observou-se lesão radiolúcida, multilocular, foi realizado biopsia incisional para exame histopatológico o qual resultou-se em lesão central de células gigantes, porem para diagnóstico conclusivo necessita-se de exames complementares para descartar outras hipóteses diagnósticas, a paciente encontra-se em tratamento com aplicações quinzenais de Triancinolona .Considerações finais: o caso relatado e publicações levantadas trazem à luz a discussão da terapêutica de uma situação complexa que é o acometimento de uma lesão agressiva em uma paciente de dez anos, diagnósticos diferenciais levantados e escolhas de tratamento adequado.

Palavras-chave: Diagnóstico diferencial, Relato de caso, Terapêutica.

\begin{abstract}
Objective: To report a case of a central lesion of giant cells in a female patient, 10 years old, leucoderma, diagnostic method and treatment of choice. Case Report: Female patient, leucoderma, 10 years of age presented in our clinical services with unilateral volume increase with symptomatic expansion for 7 months, radiographic examination showed a multilocular radiolucent lesion and an incisional biopsy was performed for examination histopathological study which resulted in a central lesion of giant cells, but for conclusive diagnosis, complementary tests are needed to rule out other diagnostic hypotheses, the patient is being treated with biweekly applications of Triamcinolone. Final considerations: the case reported and published studies bring to light the discussion of therapeutics of a complex situation that is the involvement of an aggressive lesion in a ten year old patient, raised differential diagnoses and appropriate treatment choices.
\end{abstract}

Keywords: Differential diagnosis, Case report, Therapeutic.

\section{RESUMEN}

Objetivo: Informar de un caso clínico de una lesión central de células gigantes en un paciente del género femenino, 10 años de edad, leucoderma, método diagnóstico y tratamiento de elección. Reporte de caso: Paciente femenina, leucoderma, 10 años de edad presentada en nuestros servicios clínicos con aumento de volumen unilateral con expansión sintomática durante 7 meses, examen radiográfico que mostró una lesión radiotransparente multilocular y una biopsia incisional para estudio histopatológico de examen que resultó en una central lesión de células gigantes, pero para el diagnóstico concluyente, se necesitan pruebas complementarias para descartar otras hipótesis diagnósticas, el paciente está siendo tratado con aplicaciones quincenales de triamcinolona Consideraciones finales: el caso relatado y publicaciones levantadas traen a la luz la discusión de la terapéutica de una situación compleja que es el acometimiento de una lesión agresiva en una paciente de diez años, diagnósticos diferenciales levantados y opciones de tratamiento adecuado.

Palabras clave: Diagnóstico diferencial, Relato de caso, Terapêutica.

SUBMETIDO EM: 7/2018

ACEITO EM: 8/2018

PUBLICADO EM: 12/2018

\footnotetext{
${ }^{1}$ Faculdades Unidas do Norte de Minas (FUNORTE), Montes Claros-MG.

*E-mail: wericasuzana20@gmail.com
} 


\section{INTRODUÇÃO}

Largamente considerada como uma neoplasia benigna dos ossos maxilares, a lesão central de células gigantes (LCCG) apresenta-se, tipicamente, como uma lesão radiolúcida unilocular na mandíbula e maxila (REGEZI e SCIUBBA, 2000).

É caracterizada por ser uma lesão benigna, intraóssea com múltiplos focos de hemorragia, células gigantes e trabéculas de tecido ósseo. De origem incerta, essa lesão é definida como originada de causas locais como trauma, hemorragia intraóssea e/ou causas sistêmicas que o relacionam com síndromes como a de neurofibromatose, Noonan e distúrbios hormonais do hiperparatireoidismo (FELIN et al., 2014).

Consoante a Melo et al. (2014), a LCCG é uma lesão incomum com predileção pelo gênero feminino, crianças e adultos jovens e pela mandíbula. A mandíbula é mais constantemente comprometida do que a maxila com uma proporção mandíbula/maxila de 2:1.

Chuong et al. (1986) em seus estudos categorizou as lesões de células gigantes centrais em agressivas e não-agressivas, segundo sua sintomatologia, crescimento rápido, perfuração da cortical óssea, reabsorção e deslocamento de elementos dentários, nesses casos, enaltecendo os exames como a tomografias computadorizadas, particularmente importante na identificação de perfuração das corticais com possível invasão de outras estruturas como seios da face, fossas nasais e assoalho bucal. Além disso, as agressivas mostrariam alta predisposição a recidiva após o tratamento, em relação ao tipo não-agressivo.

Radiograficamente a lesão pode assemelhar-se a outras lesões que acomete os ossos gnáticos, não sendo assim um achado diagnóstico patognomônico. Lesões como o cisto aneurismático, displasia fibrosaóssea, tumor marrom do hiperparatireoidismo ou outras são frequentemente citadas como diagnóstico diferencial da LCCG. Lesões que se apresentam radiograficamente como sendo uniloculares e de menor tamanho podem ser confundidas com granulomas ou cistos periapicais, e as lesões multiloculares podem ser confundidas radiograficamente com ameloblastomas ou outras lesões multiloculares. Quando se apresentam na maxila, a LCCG pode invadir as fossas nasais como o assoalho do seio maxilar ou órbita. Quando na mandíbula, ela é capaz de causar expansão e perfurar as corticais óssea. A presença de deslocamento dentário ou reabsorção radicular é frequentemente observado (CORSO et al., 2012; ORZECHOWZKI et al., 2012; SILVA et al., 2012; NOLETO et al., 2007; FELIN et al., 2014).

Algumas lesões são indistinguíveis ao exame histopatológico por apresentarem a mesma característica histológica, que é o caso da lesão central de células gigantes que é indistinguível com varias patologias dentre as quais o tumor marrom do hiperparatireoidismo e o cisto ósseo aneurismático (NOGUEIRA et al., 2004). Verifica-se no exame histológico da LCCG, células gigantes multinucleadas com a presença de vários núcleos, nucléolos distantes e permeados por um citoplasma eosinófilo abundante. Ainda são observados, na lâmina própria histiócitos, fibroblastos, linfócitos, eritrócitos células endoteliais, capilares venosos, pigmentos de hemossiderina e a possibilidade de neoformação óssea (CHUONG et al., 1986; POTTER, 1993).

De acordo a Trento et al. (2009) pela inviabilidade de distinção clínica, radiográfica e histopatológica de outras lesões patológicas como o Tumor marrom do hiperparatireoidismo a realização de exames complementares de laboratório de análise clínica é fundamental, alcançando-se o diagnóstico final quando os valores do fósforo, calcemia e fosfatase alcalina se apresentarem dentro da normalidade.

A ressecção em bloco, tratamento preconizado para tumores mais agressivos e recorrentes, ocasiona grandes defeitos faciais e perda de elementos dentários, o que particularmente é multilante em crianças e adultos jovens. Uma extensa reconstrução, nesses casos, é necessária para restabelecer a função e a anatomia (CORSO et al., 2012).

Em suma, o objetivo desse trabalho é relatar o caso clínico de lesão central de células gigantes em paciente do gênero feminino, com 10 anos de idade, apresentando suas características clínicas e radiográficas e discutir sobre as formas de tratamento. 


\section{RELATO DE CASO}

Paciente V.S.F.S, 10 anos, leucoderma, gênero feminino, compareceu a clínica das faculdades unidas do norte de minas - FUNORTE, na disciplina de clínica de diagnóstico bucal, com queixa principal de aumento de volume unilateral da face direita e dor.

Durante a anamnese a paciente e os responsáveis relataram que a lesão era assintomática, porém foi sendo percebida pelos pais há pelo menos 7 meses o qual veio acompanhada de cefaleia, odinofagia e disfagia.

Na história médica a paciente relatou que seu estado de saúde é "médio" e que já teve catapora, doenças pulmonares, ansiedade, herpes e falta de ar. De igual forma, relatou que escova duas vezes ao dia e faz uso do fio dental apenas quando vai ao dentista. O responsável relatou ter procurado serviços médicos como médicos pediatras e oftalmologista o qual não diagnosticou o problema.

Ao exame clínico observou-se dentição mista, assimetria facial no terço inferior da face unilateral, grânulos de fordyce, estalidos e dor ao abrir a boca nos movimentos bordejantes (Figura 1).

Figura 1. A) Assimetria Facial com aumento de volume unilateral direito no terço inferior da face; B) Aspectos clínicos intrabucal frontal; C) - Aspecto clinico intrabucal lateral.

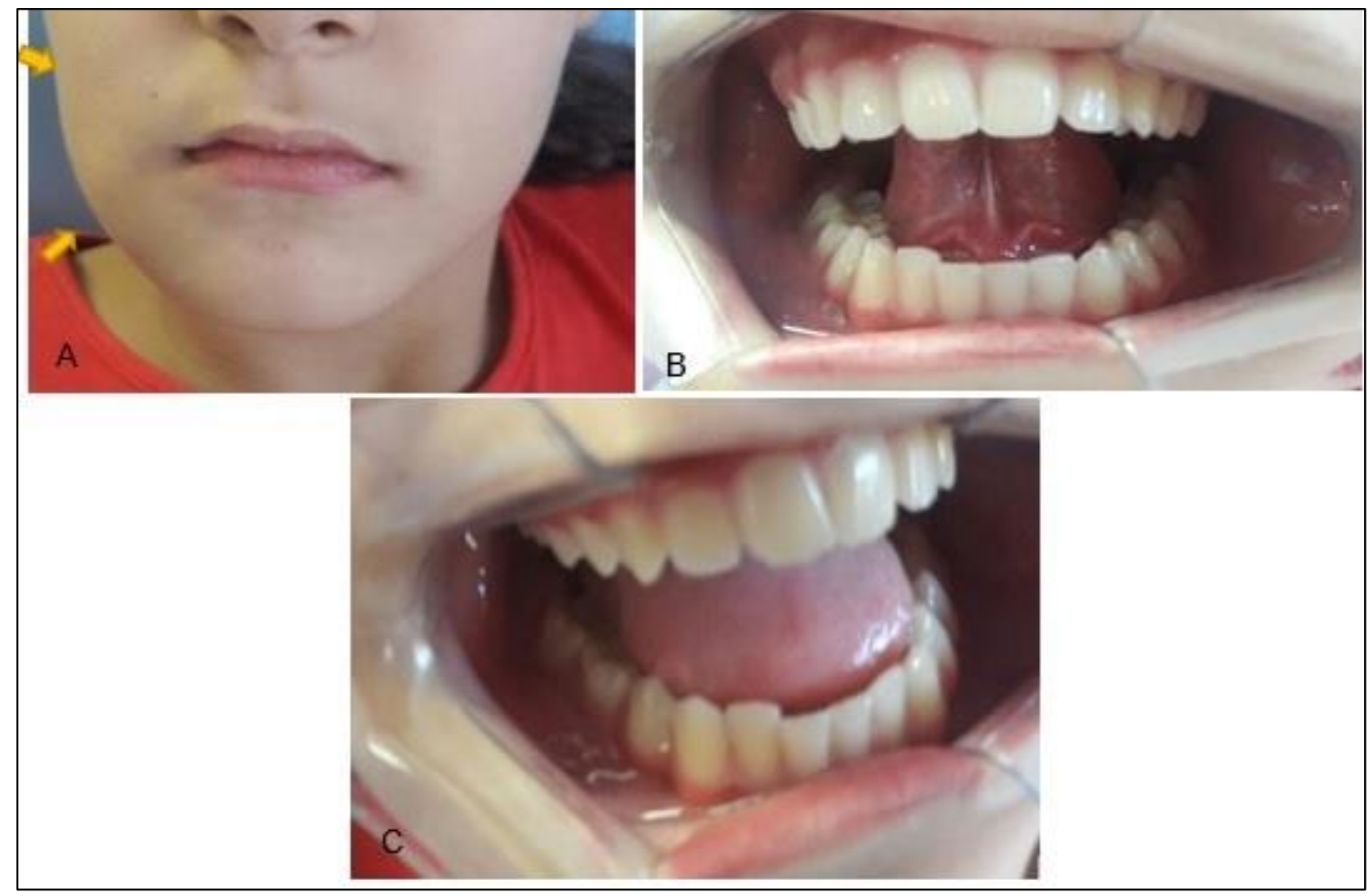

Fonte: Arquivo FUNORTE, 2017.

Com base nisso, foi solicitada radiografia panorâmica. Ao exame radiográfico observou-se uma lesão extensa, circunscrita e multilocular. Diante deste aspecto radiográfico osteolítico (redução óssea) importante, foi solicitada tomografia computadorizada para melhor avaliação da lesão (Figura 2). 
Figura 2. A) LCCG no corpo mandibular do lado direito manifestando-se como imagem radiolúcida multilocular de contorno bem definido; B) Reconstrução óssea 3d de tomografia da mandíbula com a presença de reabsorção das raízes dos elementos 42, 43 e 44.; C) Radiografia panorâmica demostrando uma área radiolúcida sugestiva de lesão tumoral
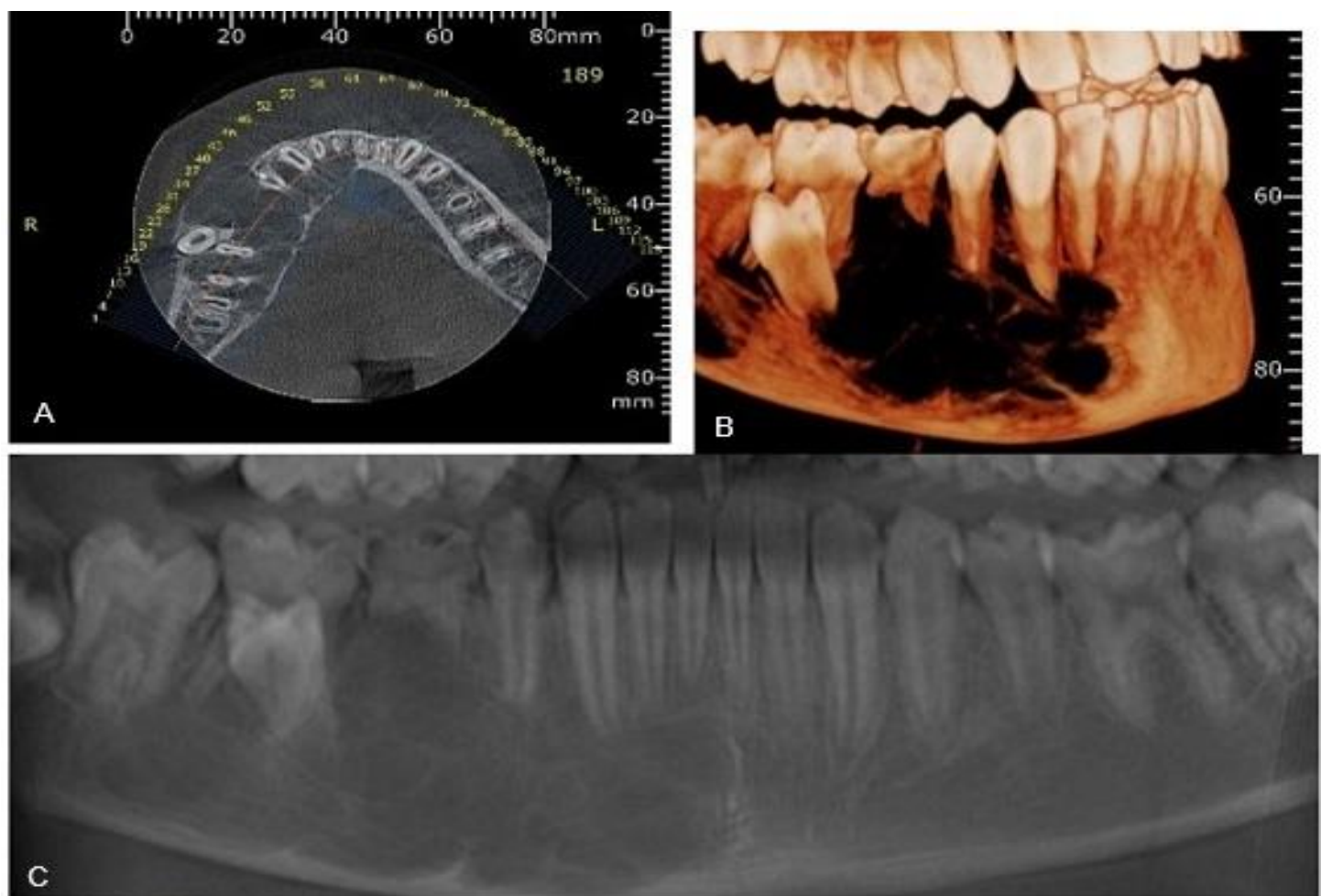

Fonte: Arquivo FUNORTE, 2017.

Na tomografia observou-se que o tumor era mais extenso do que sua apresentação na radiografia panorâmica, mostrando com clareza o tamanho da massa tumoral e expansão óssea proporcionada pelo mesmo (de $10 \times 5 \mathrm{~mm}$ com tabua óssea vestibular e lingual espesso).

Observou-se cortes da tomografia computadorizada grande área hipodensa, multilocular (formato de bolha de sabão), apresentando halo hiperdenso no seu interior, localizado na região óssea alveolar da mandíbula correspondente a área de terceiro molar direito a região do elemento 31, cortes 6 a 62, onde foi possível observar deslocamento do segundo pré-molar inferior esquerdo para a região disto-vestibular, indicado no corte 26, expansão da cortical óssea para lingual e vestibular em toda sua extensão com focos de solução de continuidade na porção vestibular indicada pela seta no corte 33 (Figura 3), e reabsorção radicular externa na raiz distal do elemento 46, na raiz vestibular dos elementos 44,43 e 42 , sendo levantada as hipóteses diagnósticas de ameloblastoma multilocular e tumor odontogênico queratocístico.

Por conseguinte, foi realizado biopsia incisional para estudo histopatológico e prescrito antibiótico e analgésico para prevenção de infecção e dor (Figura 4). O exame histológico evidenciou fragmentos de tecido conjuntivo exibindo proliferação densa de células ora fusiformes e com cromatina homogênea ora ovóides, de aspecto histiocítico, com núcleo vesicular. Múltiplas células gigantes multinucleadas podem ser notadas entremeando esta população celular, além da presença constante de hemorragia e focos de osteóide. Completa o quadro, a presença de trabéculas de osso lamelar maduro com aparência de normalidade em adjacência às alterações descritas (Figura 5). A conclusão do exame histopatológico foi compatível com Lesão Central de Células Gigantes, porém é necessária uma interpretação clínica considerando um diagnóstico diferencial com tumor marrom, querubismo e até mesmo cisto ósseo aneurismático. 
Figura 3. A) Corte 26 da tomografia exibindo deslocamento do segundo pré-molar inferior esquerdo para a região disto-vestibular, B) Corte 33 da tomografia exibindo expansão da cortical óssea para lingual e vestibular em toda sua extensão com focos de solução de continuidade na porção vestibular.
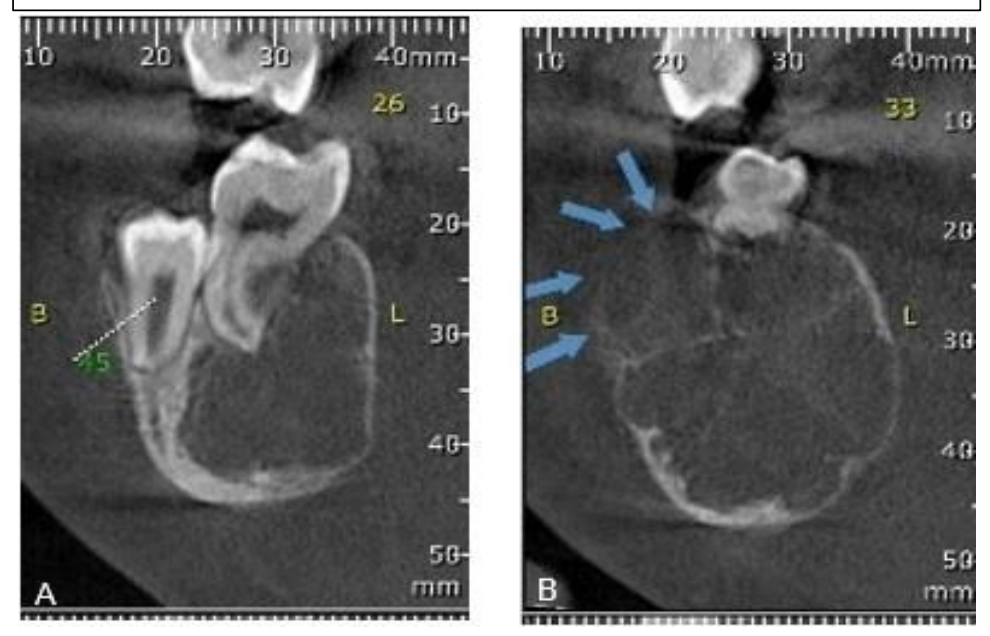

Fonte: Arquivo FUNORTE, 2017.
Foram solicitados novos exames. Bioquímico sanguíneo para estudos da ureia, creatinina, fosfotases alcalinas, hemograma completo, coagulação sanguínea e os hormônios da tireoide (T3 e T4) para diagnóstico conclusivo. Entretanto, os exames solicitados estavam dentro da normalidade e apenas a fosfatase alcalina que se encontrava bastante alterada que sob a ótica de Emanuelli et al (2008) ocorre devido a um aumento de atividade osteoblástica e/ou de hormônios. Os valores plasmáticos de cálcio e fosfatase alcalina acima do limite permitido e o fósforo reduzido são indicadores de hiperparatireoidismo, o que não acontece em pacientes com LCCG (REGEZI e SCIUBBA, 1991).

A ressecção cirúrgica em associação a curetagem agressiva é o método mais utilizado para LCCG (LANGE et al., 2007). Deve-se optar pela ressecção quando há lesões recorrentes e agressivas. Por ser usualmente encontrado em crianças e jovens adultos considera-se esse tratamento um método desfigurante e uma cirurgia agressiva (CORSO et al., 2012).

No relato aqui reportado, o tratamento cirúrgico com curetagem agressiva não foi preconizado por se tratar de uma criança e tal tratamento causar uma deformidade facial muito grande, além de problemas psicológicos. Optou-se então por injeções de corticosteroides intralesionais de triancil (Figura 7), devido a um grande relato de sucesso na literatura pesquisada (FELIN et al., 2014; ORZECHOWSKI et al., 2012; SILVA et al., 2013) e espera-se que a lesão sofra regressão. Dessa forma, estão sendo ministradas injeções de corticosteroides e logo após será realizada nova tomografia para comparação e comprovação se houve ou não regressão da lesão.

Figura 4. Biopsia incisional no lado direito, evidenciando um pouco do tumor para posterior (A e B).
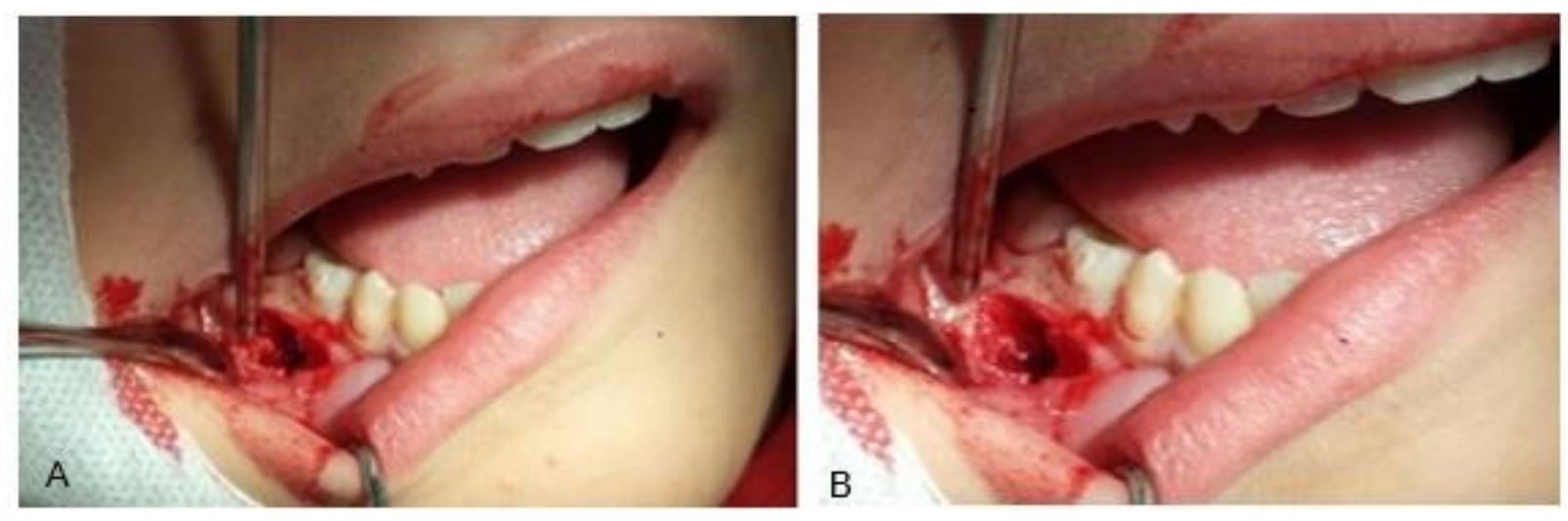

Fonte: Arquivo FUNORTE, 2017. 
Figura 5 - Exame histopatológico.

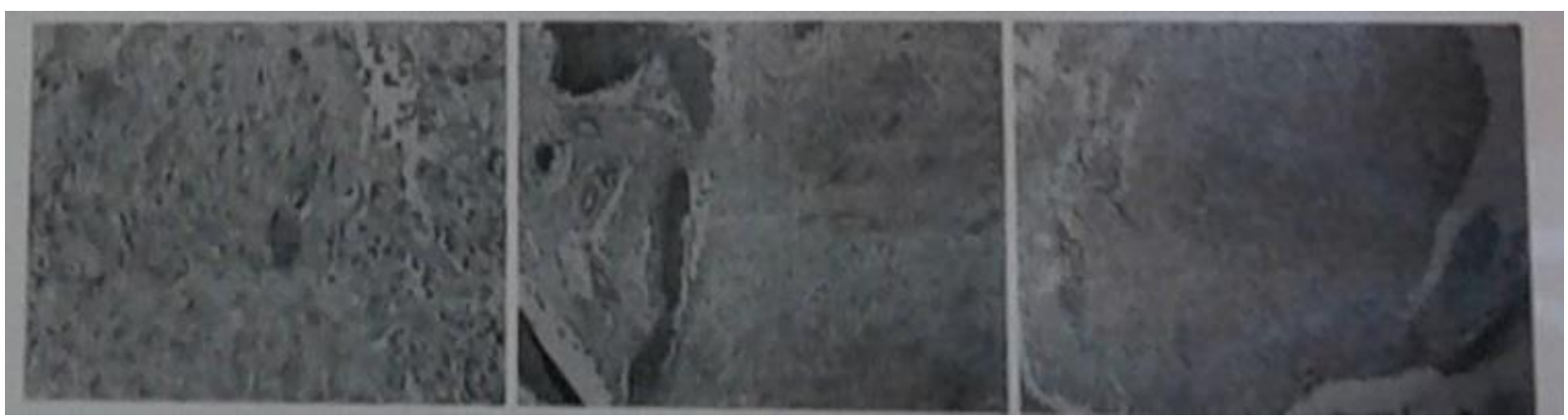

Fonte: Arquivo FUNORTE, 2017.

\section{DISCUSSÃO}

É objetivo do presente artigo relatar um interessante caso de LCCG abordando seus aspectos clínicocirúrgicos, epidemiológicos, diagnóstico diferencial e os tratamentos sugeridos na literatura. Dessa forma, dividiremos em subtópicos as questões aqui levantadas.

\section{Aspectos clínicos}

As LCCG são lesões normalmente assintomáticas, com manifestação em mandíbula e prevalência de ocorrência na região anterior. O comportamento clínico desse tipo de lesão é variável, podem ser lesões não agressivas apresentando-se como assintomático, com crescimento lento, até uma lesão agressiva com sintomatologia dolorosa, destruição óssea, deslocamento dental e reabsorção radicular (LUCA, 2009).

A lesão relatada nesse caso era, inicialmente, assintomática, porém com o passar do tempo e com o crescimento rápido e reabsorção radicular dos dentes adjacentes, passou a se tornar sintomática. Ademais, a paciente acima relatada apresentou como queixa principal o aumento de volume unilateral de rápido aparecimento o que nos levou a classificá-la como agressiva. Essa classificação tornou-se fundamental na elaboração do plano de tratamento inicial da paciente.

\section{Epidemiologia}

De acordo com os dados epidemiológicos, a LCCG acomete, em sua maioria, crianças ou adultos com menos de 30 anos, possui uma forte predileção pelo gênero feminino e geralmente envolve a mandíbula ou a maxila podendo ser localmente agressiva ou não, resultando em grandes destruições tecidual. É uma lesão benigna, com representação de $7 \%$ de todas as lesões maxilares, com predileção pela mandíbula em região anterior e aparência radiográfica radiolúcida uni ou multilocular (LUCA, 2009; CARLOS e SEDANO, 2002; KURTZ et al., 2001).

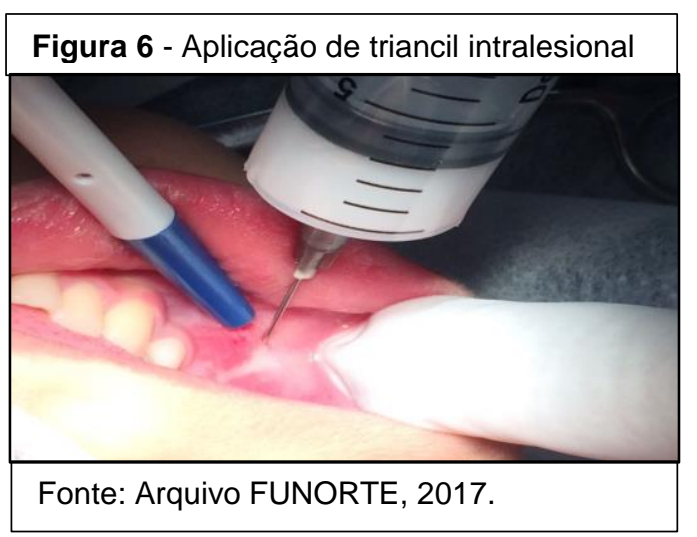

O caso aqui relatado ocorreu em uma paciente do sexo feminino, com apenas 10 anos de idade, na mandíbula em região posterior que, de acordo a literatura, se apresenta em sua forma agressiva, com aspecto radiográfico multilocular.

\section{Diagnóstico diferencial}

O diagnóstico diferencial é uma importante ferramenta para levar o clínico a melhor e mais correta conduta. Diante disso é importante considerar seus aspecto clínicos e radiográficos, localização periosteal em casos de granuloma periférico de células gigantes (GPCG) ou endosteal no granuloma central de células gigantes (GCCG), histórico de trauma em relação 
ao cisto ósseo aneurismático e possíveis alterações endócrinas, especialmente hiperparatireoidismo, na etiologia para lesões central de células gigantes dos ossos maxilares (OKADA et al., 2000; VIKRAM et al., 2000; KAR et al., 2001).

Com base nos estudos de Luca (2009) embora já esteja estabelecido as características clinicas e radiográficas da LCCG o diagnóstico diferencial deve ser estabelecido com outras patologias como o tumor marrom do hiperparatireoidismo, cisto ósseo aneurismático e o querubismo. Para diagnóstico conclusivo é necessário a realização de exames complementares como o cálcio, fosfatase alcalina, sódio, potássio e níveis de PTH intacto.

Mediante um detalhado estudo, os autores descartaram a presença de síndromes ou patologias sistêmicas na paciente, tendo como diagnóstico definitivo a LCCG.

\section{Tratamento}

Com base no trabalho realizado por Silva et al (2012) quando priorizar por algum tratamento cirúrgico ou não cirúrgico, deve-se ponderar sobre as características físicas da lesão, especialmente a dimensão e proximidade com estruturas anatômicas de relevância, além da inclusão ou não de elementos dentais, sendo o tratamento preferencial a enucleação e a curetagem cirúrgica, empregando enxertos ósseos e implantes dentários para recuperar as áreas acometidas pela lesão.

Ainda em seus estudos, Orzechowzki et al (2012) apregoa que o tratamento para LCCG pode ser realizado de diferentes maneiras, desde uma abordagem mais agressivas, como a ressecção em bloco a aplicações de medicação intralesional. $O$ tratamento de escolha depende de suas características e da sua agressividade.

Sob a ótica de Felin et al (2014) o tratamento de eleição é a curetagem, pois apresenta baixo grau de recidiva após realização, podendo ser complementado, em alguns casos, com osteotomia periférica, laser terapia ou crioterapia. Em lesões mais agressivas, onde se encontra perfuração da cortical óssea e envolvimento de tecidos moles, é recomendado a ressecção em bloco. Entretanto, defende que a ocorrência de lesões agressivas em crianças, quando optado por um tratamento mais agressivo, ocasiona, além de trauma psicológico, problemas estéticos e funcionais necessitando assim de análise de tratamentos mais conservadores.

Em contrapartida, Silva et al (2013) apregoa que a utilização da aplicação de triancinolona é muito vantajosa pois minimiza a necessidade de amplas ressecções ósseas e a perda de elementos dentários, e em alguns casos relatados a involução completa da lesão sem sinais de recorrência.

Ainda em consonância a Silva et al (2013), diversos são os tratamentos para as LCCG, e sua utilização varia de acordo a sua forma clínica apresentada. As aplicações de triancinolona e a curetagem seguida de osteotomia periférica se mostraram eficazes para essa lesão, impedindo a perca de elementos dentários e a formação de grandes defeitos ósseos.

Segundo Corso et al (2012), a calcitonina é um significativo hormônio produzido pela tireoide que produz a diminuição na circulação de cálcio. A atividade sobre o LCCG explica-se através das células gigantes que possuem receptores de calcitonina, o que modificaria seu metabolismo osteoclástico. A calcitonina pode ser empregada por intervalos de tempo mais curtos de tempo em conformação de injeções hipodérmicos ( 1 a 3 meses) ou em forma de spray nasal (6 meses a 2 anos), sendo a calcitonina de salmão.

Ainda sob a luz de Corso et al (2012) o interferon é antiangiogênico e antiviral o qual atua anulando a geração de fatores de crescimento fibroblásticos (FGF). A observação clínica de que LCCGs agressivos são altamente vascularizados e, o fato de o IFN ter sido bem avaliado em tratamentos de hemangiomas infantis, levam à hipótese de que LCCGs proliferativos são lesões com grande componente vascular e que, eventualmente, respondem à terapia antiangiogênica.

Segundo Felin et al (2014) a principal vantagem do medicamento intralesional com corticosteroide é a sua aplicação ser uma técnica simples e que incentiva a proliferação e a distinção de antecessores de osteoclastos e interrompe a reabsorção óssea por meio do impedimento da atividade apoptótica de células 
similar a osteoclastos e de produção extracelular de proteases. Com base em com alguns estudos, devem ser empregados a injeção semanal de Triancinolona $10 \mathrm{mg} / \mathrm{ml}$ associada à lidocaína a 0,5\% (partes iguais), numa dose de $2 \mathrm{ml}$ de solução para cada $2 \mathrm{~cm}$ de radiolucidez, em lugares diferentes da lesão, por no mínimo seis semanas. Evidências cientificas comprovam que uma nova formação óssea aparece após três meses de uso continuo. É contraindicado o uso desse corticoide em pacientes que possuem diabete mellitus, infecção, úlcera péptica e sistema imunológico comprometido.

Ainda sob a ótica de Felin et al (2014), a aplicação de injeção intralesional com corticoide é bem relatado por vários autores, aplicando em pacientes jovens, seus efeitos evitam que estruturas vitais sejam prejudicadas, reduzindo assim as chances de grandes deformidades faciais. De acordo com o autor, entre os casos tratados com corticoide, dez pacientes apresentaram lesão agressiva e onze pacientes com lesões não agressivas, dentre eles apenas dois reagiu negativamente ao tratamento e optou-se pela ressecção cirúrgica. Dessa forma, e importante ressaltar que antes de optar por uma cirurgia radical, deve-se considerar o uso desse tratamento.

A radioterapia não é um tratamento adotado para se tratar da LCCG, pois possui o poder de transformação maligna das células gigantes em osteosarcoma. (CORSO et al., 2012; SILVA et al.,2012).

Destarte considera-se que aplicações de triancinolona como opção de tratamento não cirúrgico é uma boa escolha para essa lesão, principalmente por se tratar de um método simples, de fácil execução e com a preservação das estruturas anatômicas, evitando deformidades faciais severas.

No caso relatado, considerando a idade da paciente e a extensão da lesão, foi optado por aplicação intralesional de triancinolona, bem como ao rigoroso e periódico controle clínico e radiográfico. Essa técnica não cirúrgica é uma excelente opção de tratamento, especialmente em crianças e adultos jovens, em comparação com os efeitos da cirurgia agressiva sobre o crescimento dos ossos da face e, também, traz menos danos aos dentes adjacentes.

\section{CONSIDERAÇÕES FINAIS}

O caso relatado nesse presente artigo trouxe a luz questões como diagnóstico diferencial tanto radiológico, quanto histopatológico, levantando a questão da importância de um diagnóstico precoce que diminuir-se-ia a evolução rápida e dolorosa da lesão bem como a utilização de terapias agressivas.

De tal maneira, é importante ressaltar a importancia do levantamento de diagnósticos diferencias e sua correta interpretação clínica através da correta leitura de exames radiográficos, tomográficos, sanguíneos e anatomopatológicos. Dessarte, é importante um correto planejamento do tratamento frente as diferenças clínicas apresentadas pela LCCG vislumbrando sucesso no tratamento e evitando recidivas ou complicações.

A paciente relatada no presente artigo encontra-se em tratamento com aplicação quinzenal de triancil, o qual está surtindo efeito e já se observa uma nova formação óssea, principalmente por vestibular, acreditase que será um caso finalizado com sucesso clinico.

\section{REFERÊNCIAS}

1. CARLOS R, SEDANO HO. Intralesional corticosteroids as na alternative treatment for central giant cell granuloma. Oral surgery, oral medicine, oral pathology and oral radiology endodontics, 2002; 93(2): 161-166.

2. CHUONG R, KABAN LB, KOZAKEWICH H, PEREZ-ATAYDE A. Central Giant Cell Lesions of the Jaws: A Clinicopathologic Study. J Oral Maxillofac Surg. 1986; 44:708-13.

3. CORSO PFCL, NASCIMENTO LC, COSTA DJ et al. Tratamento de lesão central de células gigantes recidivante: relato de caso. Rev. Cir. traumatol. buco-maxilo-fac. Camaragibe, 2012; 12(3).

4. EMANUELLI MP, LOPES STA, MACIEL RM et al. Concentração sérica de fosfatase alcalina, gama-glutamil transferase, uréia e creatinina em coelhos (oryctolagus cuniculus). Ciência Animal Brasileira, 2008; 9(1): 251-25.

5. FELIN GC, ZANATA A, ROCHA G et al. Tratamento com corticosteroide de granuloma central de células gigantes mandibular em criança: relato de caso. RFO UPF, Passo Fundo, 2014; 19(3). 
6. KAR DK, GUPTA SK, AGARWAI A et al. Brown tumor of thepalate and mandibuble inn association with primary hyperparathyroidism. Journal of oral maxillofacial Surgery, 2001; 59: 1352-1354.

7. KURTZ J, MESA M, ALBERTO P. Treatment of a central giant cell lesion of the mandible with intralesional glucocorticosteroids. Oral surg. Oral Med. Oral Pathol. Oral Radiol. Endod., St. Louis, 2001; 91(6): 636-637.

8. LANGE J, AKKER HPV, BERG HV. Central giant cell granuloma of the jaw: a review of the literature with emphasis on therapy options. Oral Surg Oral Med Oral Pathol Oral RadiolEndod, 2007; 104: 603-615

9. LUCA GC. Granuloma central de células gigantes: revisão de literatura. Dissertação (Especialização em radiologia e Imaginologia) - Faculdade de Ciência biológicas e de saúde da universidade Tuiuti do Paraná, Curitiba, 2009.

10. MELO RB, SILVA, PF, GONÇALVES FLN et al. Tratamento cirúrgico de granuloma central de celulas gigantes agressivo em maxilacom acesso weber ferguson: relato de caso. Rev. Cir. Traumatol. Buco-Maxilo-Fac., Camaragibe, 2014; 14(4):65-70, out./dez.

11. NOGUEIRA RLM, CAVALCANTE RB, CARVALHO ACGS et al. Lesão de células gigantes: um estudo do diagnóstico diferencial em 04 casos clínicos. Revista de cirurgia e traumatologia BMF, 2004; 4(2): 81-89.

12. NOLETO JW, MARCHIORI E, SAMPAIO RK et al. Aspectos radiológicos e epidemiológicos do granuloma central de células gigantes. Radiol. Bras, São Paulo, 2007; 40(3): 167-17.

13. OKADA H, Davies JE, Yamamoto $H$. Brown tumor of the maxilla in a patiente with secondary hyperparathyroidism: a case study involving immunohistochemistry and electron microscopy. Jornal oral maxillofac surg, 2000; 58: $233-238$.

14. ORZECHOWSKI PR, TAKASHIMA M, ROMEIRO RL et al. Granuloma Central de Células Gigantes: Relato de Caso Clínico. Rev. cir. traumatol. buco-maxilo-fac, Camaragibe, 2012; 12(4).

15. POTTER JB, TINER BD. Central giant cell granuloma: report of a case. Oral surgery, oral medicine and oral pathology, 1993; 75(4): 286-289.

16. REGEZI JA, SCIUBBA JJ. Patologia buccal: correlações clínicopatológicas. Philadelphia: Saunders, 1991.

17. REGEZI JA, SCIUBBA JJ. Patologia bucal: correlações clinicopatológicas. $3^{a}$ ed. Rio de Janeiro: Guanabara Koogan, 2000: 330-332.

18. SILVA CEXSR, HECHT A, PACCA FOT et al. Lesão central de células gigantes: relato de um caso clínico. Rev Assoc. Paul. Cir. Dent, 2012; 66(4): 298-301.

19. SILVA LF, PIMENTEL, GG, BENEVIDES BS et al. Tratamento combinado de granuloma central de células gigantes por meio de corticoterapia e enucleação: relato de caso. Rev. Cir. Traumatol. Buco-Maxilo-Fac. Camaragibe, 2013; 13(4): 09-14.

20. TRENTO CL, CASTRO EVFL, FRANÇA DCC et al. Lesão de células gigantes central: relato de caso. Rev. Cir. Traumatol. Buco-Maxilo-fac., Camaragibe, 2009; 9(4): 39 - 44, out./dez.

21. VIKRAM HR, PETITO A, BOWER BF et al. Parathyroid carcinoma diagnosed on the basis of a giant lesion of the maxilla, Jornaul of Oral Maxillofacial surgery, 2000; 58: 567-569. 